\title{
Compostagem e vermicompostagem como alternativa para tratamento e destinação de resíduos orgânicos
}

\section{Composting and vermicomposting as an alternative for treatment and disposal of organic waste}

\author{
Larissa Morais Sena $\mathbb{\mathbb { D }}^{\prime}$, Julyanne Fonteles de Arruda $\mathbb{D}^{1}$, Francisca Raíssa da Silva Costa $\mathbb{D}^{1}$, Fabiana \\ Barbosa Braz de Almeida $\mathbb{D}^{2}$, Paulo Ovídio Batista de Brito $\mathbb{D}^{3}$, Franklin Aragão Gondim $\mathbb{D}^{4 *}$
}

\begin{abstract}
${ }^{1}$ Graduandas em Engenharia Ambiental e Sanitária, Instituto Federal de Educação Ciência e Tecnologia do Ceará (IFCE), Campus Maracanaú, larissamoraissena@gmail.com, julyannefarruda@yahoo.com.br, raissacosta55@yahoo.com; ${ }^{2}$ Mestre pelo Programa Pós-Graduação em Energias Renováveis (PPGER) IFCE Campus Maracanaú, fabianabraz13@hotmail.com; ${ }^{3}$ Mestrando pelo PPGER, IFCE Campus Maracanaú, paulobatistaengenharia@gmail.com; ${ }^{*}{ }^{4}$ Doutor em Bioquímica e Professor do IFCE Campus Maracanaú, aragaofg@ yahoo.com.br, +55 8538786300.
\end{abstract}

\section{A R T I G O}

Recebido: 22/11/2018

Aprovado: 14/03/2019

\section{Palavras-chave:}

Composto Orgânico

Fertilizante

Reaproveitamento

Nutrientes

\section{Key words:}

Organic compost

Fertilizer

Waste

Nutrients
R E S U M O

Os solos de regiões semiáridas apresentam naturalmente uma baixa fertilidade, dificultando $\mathrm{o}$ crescimento e a produtividade das plantas, aumentando os custos de produção, devido aos investimentos com fertilizantes e defensivos agrícolas. Além disso, globalmente existe grande desperdício de alimentos. Diante deste cenário, objetivou-se com o presente trabalho avaliar o reaproveitamento dos resíduos orgânicos para a produção de um composto orgânico por meio de compostagem, seguido de vermicompostagem. O experimento foi realizado em duas etapas (compostagem seguida de vermicompostagem), no Instituto Federal de Educação Ciência e Tecnologia do Ceará Campus Maracanaú. Foram utilizados resíduos orgânicos alimentares, provenientes da Central de Abastecimento do Ceará, esterco bovino e folhas secas. Aos 51 dias após o início da compostagem, o composto foi colocado em um depósito com capacidade de $310 \mathrm{~L}$ e foram adicionadas 100 minhocas californianas adultas (Eisenia foetida), iniciando assim o processo de vermicompostagem. Concluiu-se que é possível utilizar os resíduos alimentares para a produção de composto orgânico fertilizante. A compostagem seguida de vermicompostagem mostrou-se viável e de fácil aplicação. A vermicompostagem diminuiu a granulometria do composto e melhorou a qualidade nutricional do material, aumentando os teores de fósforo, cálcio, zinco, cobre e ferro.

\section{A B S T R A C T}

The gray water footprint (GWF) is defined as the volume of fresh water needed to dilute Soil of semiarid regions naturally present low fertility, hampering plant growth and productivity, increasing production costs due to investments in fertilizers and agricultural pesticides. In addition, overall, there is a great waste of food. In view of this scenario, the aim of this work was to evaluate the reuse of organic waste for the production of an organic compost by means of composting, followed by vermicomposting. The experiment was carried out in two stages (composting followed by vermicomposting), at the Federal Institute of Education Science and Technology of Ceará Campus Maracanaú. Organic food residues were used from the Ceará Supply Center, cattle manure and dry leaves. At 51 days after composting, the compost was placed in a tank with a capacity of $310 \mathrm{~L}$, and 100 adult Californian worms (Eisenia foetida) were added, thus initiating the vermicompost process. It was concluded that it is possible to use food waste for the production of organic fertilizer. Composting followed by vermicomposting was feasible and easy to apply. The vermicomposting reduced the grain size of the compound and improved the nutritional quality of the material, increasing the phosphorus, calcium, zinc, copper and iron content.

\author{
Revista Verde \\ ISSN 1981-8203 \\ Pombal, Paraíba, Brasil
}

v. 14, n.2, abr.-jun, p.266-272, 2019

doi: 10.18378/rvads.v14i2.6136 


\section{INTRODUÇÃO}

No Brasil, verifica-se um grande desperdício de alimentos, estando o país entre os 10 que mais desperdiçam alimentos no mundo, com $35 \%$ da produção agrícola sendo desperdiçada (MOURA et al., 2013). Dessa forma, esses resíduos têm como destino final os aterros sanitários ou lixões, onde são depositados com os diversos tipos de lixo, sem receber qualquer tratamento, o que gera inúmeros impactos socioambientais (COSTA et al., 2014). No Ceará, um dos locais que apresenta os maiores números de desperdício de alimentos é a Central de abastecimento (CEASA). A CEASA surgiu em 1972 com o objetivo de centralizar a distribuição de hortigrajeiros no estado. No entanto, durante o processo, são produzidas 6.504,20 toneladas de resíduos por ano, sendo $50 \%$ hortigranjeiros (CEASA, 2018).

Em contrapartida, os solos do semiárido cearense, apresentam uma baixa fertilidade natural, necessitando, para um bom desempenho agrícola, da aplicação de fertilizantes sintéticos, que adicionam nutrientes ao solo e o preparam para a agricultura. Nesse sentido, o processo de compostagem é uma das melhores alternativas para a destinação de resíduos orgânicos, evitando a degradação ambiental e permitindo a obtenção de fertilizantes para o solo. A técnica pode ser vista como uma forma de reciclagem de matéria orgânica, pois o lixo orgânico é tratado naturalmente e se transforma em uma biomassa altamente nutritiva para plantas. O processo ocorre devido à ação de microorganismos, pois na vermicompostagem há uma relação simbiótica entre as minhocas e os microorganismos do trato digestório (VALENTE et al., 2018).

A compostagem é um processo de decomposição aeróbia, em que há a liberação de gás carbônico, vapor d'água e energia. Esse processo promove a estabilização da matéria orgânica, em que os nutrientes e minerais presentes nos resíduos orgânicos, são facilmente assimilados pelas plantas (DORES-SILVA, 2013).

Através da compostagem misturam-se alimentos descartados, folhas, frutos, estercos, palhas, dentre outros, obtendo-se ao final um adubo orgânico de cor escura, homogêneo, estável, e pronto para ser utilizado na adubação de diversas culturas agrícolas, sem causar danos ambientais. $\mathrm{O}$ composto é capaz de promover melhoria nas propriedades físicas, químicas e biológicas do solo, pois auxilia na retenção de umidade, melhora a textura dos solos, dificultando assim o processo de erosão e fornecendo macro e micronutrientes às plantas (MALAFAIA et al., 2015).

Parte da energia da compostagem é usada pelos microrganismos decompositores e a outra é transformada em calor, que é conservado na pilha, resultando em altas temperaturas $\left(40-50^{\circ} \mathrm{C}\right)$. Além dos benefícios da descontaminação do material, a elevação da temperatura pode auxiliar na degradação de frações mais resistentes, como as fibras, por exemplo. De acordo com Loureiro et al. (2007), a faixa ótima de temperatura para compostagem varia entre 45 e $65^{\circ} \mathrm{C}$. Temperaturas acima de $65^{\circ} \mathrm{C}$ tornam o processo menos eficiente, e acima de $70^{\circ} \mathrm{C}$, por longo período, restringem a ação dos microrganismos mais sensíveis, insolubiliza proteínas hidrossolúveis e provoca alterações químicas indesejáveis (ORRICO JÚNIOR et al., 2010).

Em seguida, na fase de maturação do composto, ocorre a diminuição da temperatura (aproximadamente $30^{\circ} \mathrm{C}$ ), momento adequado para a utilização do composto (JARA et al., 2017). O composto pode passar também pelo processo de vermicompostagem, quando há adição de minhocas durante a decomposição, tornando o material mais rico em nutrientes devido à produção de húmus (LOUREIRO et al., 2007). Estudos têm demonstrado que a vermicompostagem, em comparação ao composto produzido sem minhocas, acelera a estabilização da matéria orgânica e produz um composto com menor razão $\mathrm{C} / \mathrm{N}$ e maior capacidade de troca catiônica (SILVA et al., 2002).

Diante do exposto, objetivou-se com o presente trabalho avaliar a possibilidade do reaproveitamento dos resíduos alimentares para a produção de um composto orgânico por meio de compostagem seguido de vermicompostagem.

\section{MATERIAL E MÉTODOS}

$\mathrm{O}$ experimento foi realizado em duas etapas, no Instituto Federal de Educação Ciência e Tecnologia do Ceará (IFCE) Campus Maracanaú. A primeira, iniciada em dezembro de 2016, consistiu na montagem de uma composteira com área de $6,5 \mathrm{~m}^{2}$ delimitada por tijolos (Figura 1). Em seguida, foram adicionados resíduos orgânicos juntamente com esterco bovino curtido adquirido comercialmente. Foram utilizados resíduos orgânicos provenientes da Central de Abastecimento do Ceará (CEASA - CE), $272 \mathrm{~kg}$ no total. Dentre os resíduos havia pimentão, banana, beterraba, melancia, batata doce, manga e outros alimentos descartados. Para facilitar o processo de decomposição, foi necessário aumentar a superfície de contato desses alimentos, portanto, eles foram cortados em pedaços com área aproximada de $4 \mathrm{~cm}^{2}$, com o auxílio de facas. Além dos restos orgânicos, foram adicionadas folhas secas, que são fontes de carbono e servem também para manutenção da umidade, e $49 \mathrm{~kg}$ de esterco bovino, usado para acelerar o processo de compostagem. O esterco é fonte de microrganismos, e a adição favorece a decomposição dos resíduos orgânicos. Na figura 1 a composteira está em formato laminar, contudo, após o revolvimento, o material foi disposto em leiras elevadas visando intensificar a ação microbiana (ORRICO JÚNIOR et al., 2010).

A segunda etapa iniciou em janeiro de 2017, quando houve uma diminuição da temperatura da pilha, que chegou a $30^{\circ} \mathrm{C}, 43$ dias após o início da primeira. Essa etapa foi feita na casa de vegetação do IFCE Campus Maracanaú, totalmente coberta por tela de plástico ("nylon") de cor preta, que proporciona sombreamento de $50 \%$. As médias de temperatura e umidade relativa do ar, durante o dia, na casa de vegetação foram, respectivamente, $31,3{ }^{\circ} \mathrm{C}$ e $59 \%$. Nessa etapa, o composto foi colocado em um depósito com capacidade para $310 \mathrm{~L}$, e foram adicionadas 100 minhocas californianas adultas (Eisenia foetida) cedidas pelo sítio Floresta localizado em Eusébio-CE, iniciando assim o processo de vermicompostagem. 
Figura 1. Resíduos orgânicos dispostos na composteira no período anterior ao corte em pequenos pedaços (A), após o corte (B), camada de esterco bovino sobre os resíduos alimentares (C) e camada de folhas secas (D).

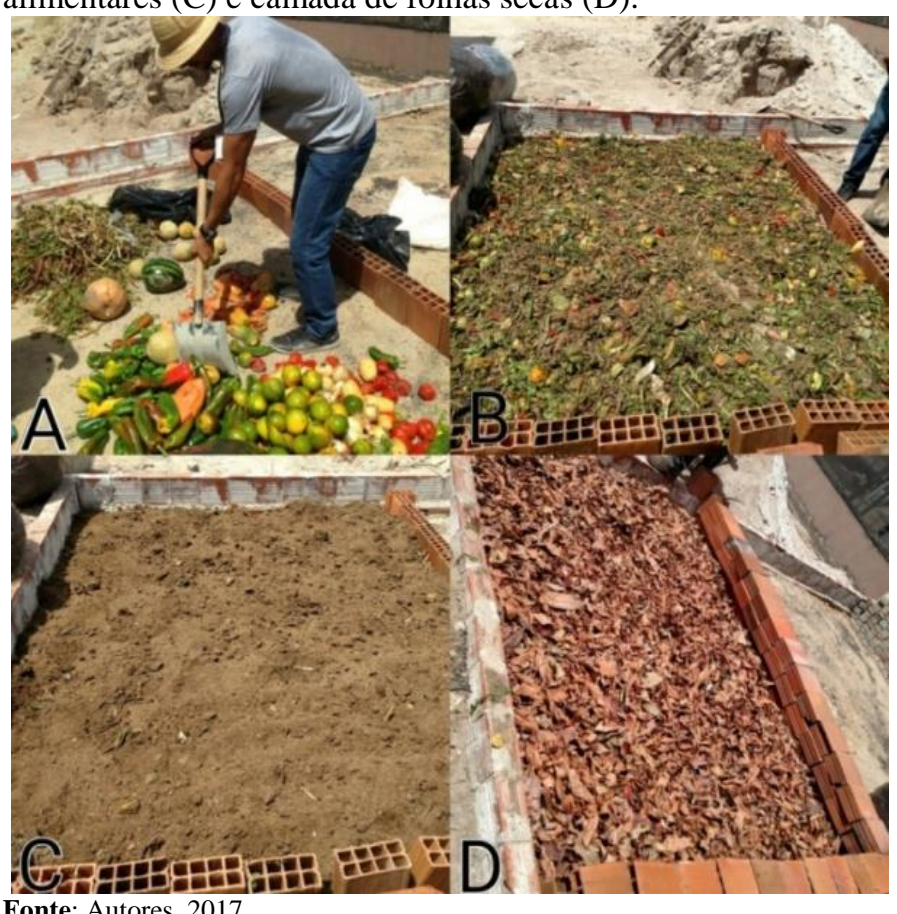

Tanto na fase de compostagem como na vermicompostagem o material passou por revolvimentos e irrigações semanais para a constante oxigenação e manutenção da umidade, essencial para a ação dos microrganismos. A temperatura foi monitorada semanalmente, através de termômetro de mercúrio, em três pontos, topo, meio e fundo da leira, usando a média desses três valores. $\mathrm{Na}$ vermicompostagem, realizaram-se medições semanais de umidade e $\mathrm{pH}$, através de medidor de $\mathrm{pH}$ e umidade para solos, também nos pontos de topo, meio e fundo da leira.

Foram retiradas amostras aos 1, 30, 45, 50, 63, 70, 85, 94, 100,107, 126 e 150 dias de compostagem e vermicompostagem para as realizações de análises químicas. Determinaram-se as concentrações de: nitrogênio, fósforo, potássio, cálcio, magnésio, ferro, cobre, zinco e manganês, no laboratório de Solos e Água da Universidade Federal do Ceará, de acordo com a metodologia de Avaliação do Estado Nutricional das Plantas (MALAVOLTA et al., 1997).

\section{RESULTADOS E DISCUSSÃO}

$\mathrm{Na}$ primeira etapa do processo, que consistiu na termoestabilização dos resíduos orgânicos com esterco, a temperatura atingiu até $45^{\circ} \mathrm{C}$ (Figura 2A). Este comportamento indica a ação de bactérias e fungos termófilos na degradação dos resíduos, até os 26 primeiros dias de compostagem (LOUREIRO et al., 2007). Entre 33 e 52 dias, houve uma queda da temperatura, que variou de 30 a $33^{\circ} \mathrm{C}$ (Figura 2B). Essa temperatura além de indicar uma possível colonização de fungos e actinomicetos no composto, evidenciou que $o$ composto estava pronto para a segunda etapa, a vermicompostagem, onde foram adicionadas as minhocas californianas (Eisenia foetida) (COTTA et al., 2015). A partir de 52 dias de compostagem, quando iniciou a vermicompostagem, a temperatura continuou diminuindo, chegando a $21,5^{\circ} \mathrm{C}$ ao final do processo (Figura $2 \mathrm{C}$ ).

Figura 2. Temperatura do material em compostagem e vermicompostagem no decorrer do tempo.

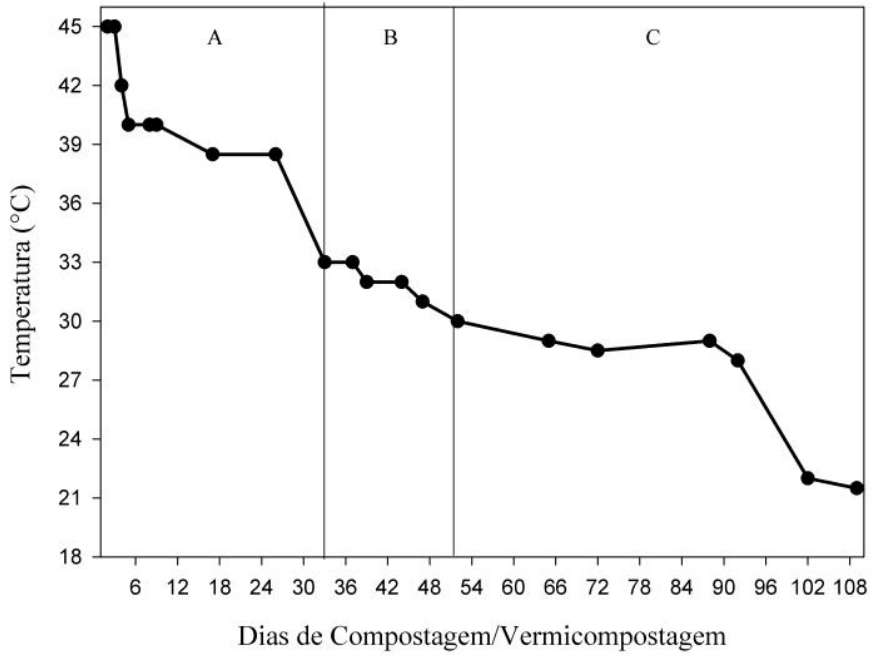

Sugere-se que a adição do esterco bovino acelerou o processo de compostagem, pois contém microrganismos, os quais são responsáveis pela conversão de diversos compostos nitrogenados em $\mathrm{NH}_{3}$, intensificando a mineralização dos resíduos orgânicos (LOUREIRO et al., 2007).

Como pode ser observado na Figura 3, ocorreu uma rápida degradação dos resíduos orgânicos. Na Figura 3A, em que o composto estava com 17 dias de compostagem, a decomposição já se encontrava bastante avançada, porém o composto ainda apresentava granulometria relativamente elevada, com resíduos orgânicos e folhas secas não decompostos. Aos 109 dias, o composto apresentou granulometria bem menor e pronto para ser utilizado como fertilizante (Figura 3B).

Figura 3. Aspectos visuais dos resíduos orgânicos em compostagem aos 17 (A) e 109 dias (B) após o início do processo.

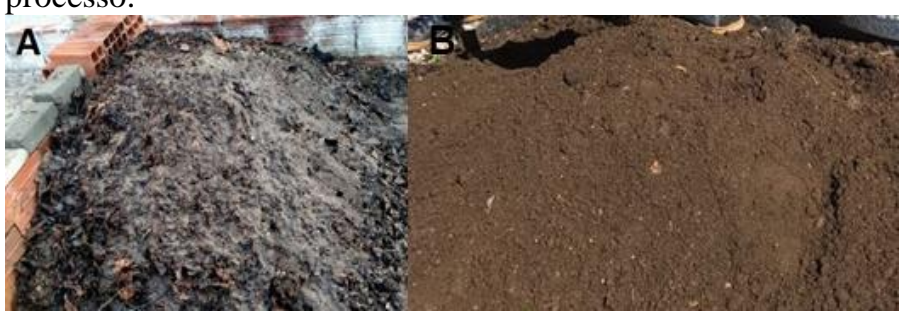

Fonte: Autores, 2017.

$\mathrm{O}$ volume do material também alterou, diminuiu cerca de $84 \%$ devido à decomposição do material e perda de água. O composto que ocupava um espaço de aproximadamente 2.000 L, passou a ocupar um espaço de $310 \mathrm{~L}$.

A umidade (Tabela 1) ficou em torno de 50 e $60 \%$, dentro da faixa de umidade ótima para se obter um máximo de decomposição (40 a 60\%). Os valores de $\mathrm{pH}$ (Tabela 1) permaneceram próximos à neutralidade durante todo o experimento. Isso sugere que o substrato estava em condições 
adequadas para a ação dos microrganismos e das minhocas. É necessário que exista um suprimento de água adequado para promover o crescimento dos organismos envolvidos no processo e para que as reações bioquímicas ocorram adequadamente durante a compostagem (MILLÁN et al., 2017).

Tabela 1. $\mathrm{pH}$ e umidade do composto na fase de vermicompostagem.

\begin{tabular}{ccc}
\hline Dias de Vermicompostagem & $\mathrm{pH}$ & Umidade $(\%)$ \\
\hline 1 & 7 & 50 \\
15 & 7 & 50,5 \\
22 & 6,5 & 63,5 \\
38 & 7 & 58 \\
42 & 6,9 & 43 \\
52 & 7 & 58 \\
59 & 7,1 & 51 \\
66 & 6,8 & 60 \\
78 & 6,7 & 60 \\
100 & 6,9 & 56 \\
\hline
\end{tabular}

A adição das 100 minhocas californianas foi essencial para a finalização do processo de maturação do composto. Ao se alimentarem do composto e eliminarem seus dejetos (húmus), as minhocas o enriquecem e mineralizam o composto. Durante o período da vermicompostagem, verificou-se uma variação na coloração do substrato, que ficou mais escuro devido à produção do húmus.

As análises químicas do material em compostagem/vermicompostagem demonstraram grandes variações nas concentrações no decorrer do tempo (Figuras 4 a 11). A medida que a matéria orgânica é consumida pelos microrganismos, as concentrações dos minerais no composto deveriam aumentar, pois os incrementos esperados nas concentrações dos minerais deveriam ser proporcionais à redução de massa seca. Com o aquecimento da massa enleirada grande parte da matéria orgânica foi perdida, principalmente na forma de $\mathrm{CO}_{2}$ e água, ocasionando assim a concentração da matéria mineral (ORRICO JÚNIOR et al., 2012).

$\mathrm{O}$ aumento nos teores dos elementos minerais é um indicativo de que o processo foi conduzido de maneira adequada. No entanto, no presente trabalho, o local onde ocorreu a compostagem não estava impermeabilizado, o depósito usado para vermicompostagem apresentava orifícios, o que permitiu a drenagem do líquido, podendo ter ocorrido lixiviação de parte dos nutrientes disponibilizados pela ação dos microrganismos. A lixiviação ocorre quando grande parte dos nutrientes se encontra na forma solúvel. Acredita-se que a lixiviação é uma das principais responsáveis pela variação dos dados encontrados na literatura (ORRICO JÚNIOR et al., 2012).

A diminuição da concentração de nitrogênio (Figura 4), na fase de compostagem pode estar relacionada com uma possível lixiviação dos nutrientes. É comum, mesmo em condições controladas a formação de uma pequena quantidade de chorume (DORES-SILVA et al., 2013).

Adicionalmente, verificou-se que na fase da vermicompostagem houve aumento na concentração de nitrogênio, o que pode indicar uma melhoria da qualidade do composto. O nitrogênio é um elemento essencial na formação das proteínas, DNA e RNA, influenciando diretamente na capacidade de reprodução e crescimento da população dos microorganismos (ORRICOJÚNIOR et al., 2012).

Figura 4. Concentração de nitrogênio no material em compostagem/vermicompostagem no decorrer do tempo. Círculos preenchidos representam o período de compostagem, enquanto os brancos o de vermicompostagem.

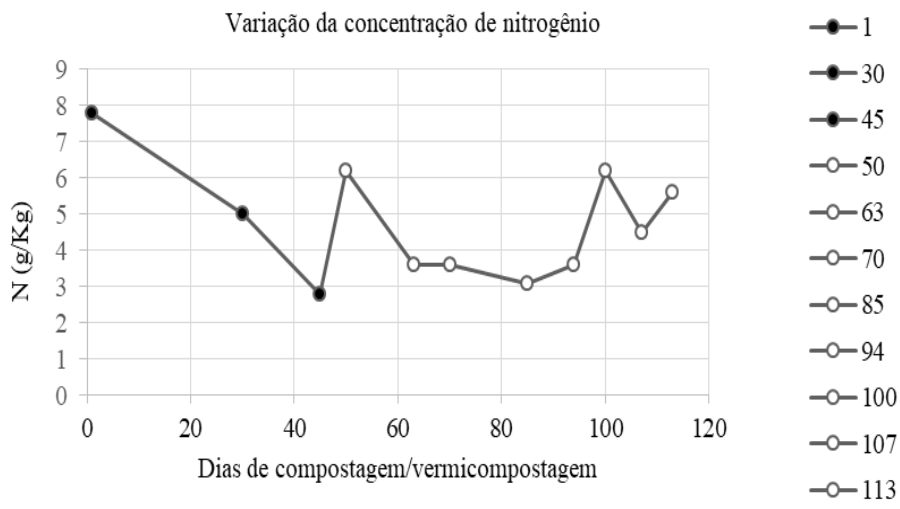

O mesmo aconteceu para a concentração de P (Figura 5), $\mathrm{Ca}$ (Figura 6), Mg (Figura 7), Fe (Figura 8) e Cu (Figura 9), cujas concentrações diminuíram durante o período de compostagem, e, em seguida, aumentaram durante o período de vermicompostagem.

O aumento dessas concentrações durante a vermicompostagem pode ser explicado pela adição das minhocas, já que ao se alimentarem do composto, suas bactérias intestinais tornam o material ainda mais rico nutricionalmente, formando assim, o húmus (VIONE; NATALE 2018). O fósforo desempenha papel importante no crescimento do sistema radicular, sendo o segundo nutriente essencial mais limitante à produção agrícola e na construção da fertilidade do solo (SOUZA, 2018). Por isso é tão importante a presença de fósforo no composto orgânico, e a Figuras 5 mostra condições positivas para o uso do composto na agricultura, ao final do processo de vermicompostagem.

Figura 5. Concentração de fósforo no material em compostagem/vermicompostagem no decorrer do tempo.

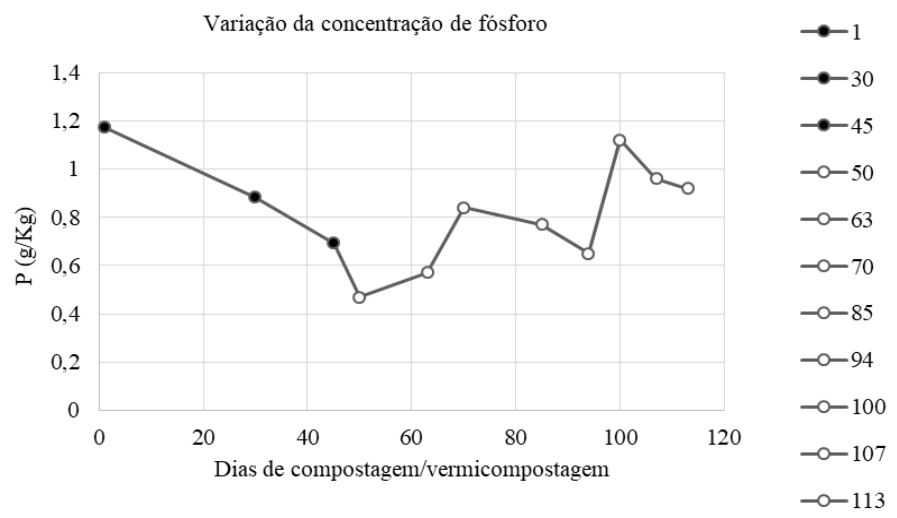

As principais funções do cálcio na planta são manter a integridade da parede celular, e auxiliar no crescimento radicular. Com a diminuição da concentração de cálcio no solo, 
pode ocorrer forte limitação ao crescimento radicular na maioria das espécies cultivadas (PRADO, 2004). Portanto, a presença de cálcio na solução do solo, em contato com o sistema radicular é essencial à sobrevivência das plantas, por isso, o aumento da concentração desse elemento no composto durante a vermicompostagem mostrou-se relevante (Figura 6).

Figura 6. Concentração de cálcio no material em compostagem/vermicompostagem no decorrer do tempo.

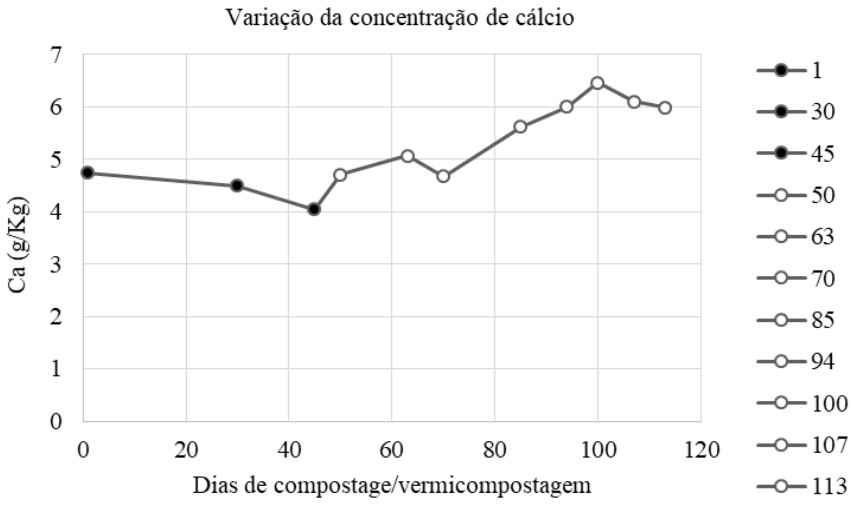

O magnésio é essencial na fotossíntese, pois participa dos processos metabólicos como a formação de trifosfato de adenosina (ATP) nos cloroplastos, além de atuar na síntese proteica, formação de clorofila, carregamento do floema e separação e utilização de fotoassimilados (BACKES, 2018).

Devido ao magnésio estar relacionado às diversas reações fundamentais, o solo necessita apresentar concentrações adequadas desse nutriente para o crescimento das plantas. Porém, no presente trabalho, não houve elevação das concentrações de magnésio (Figura 7) durante o período de compostagem/vermicompostagem.

Figura 7. Concentração de magnésio no material em compostagem/vermicompostagem no decorrer do tempo.

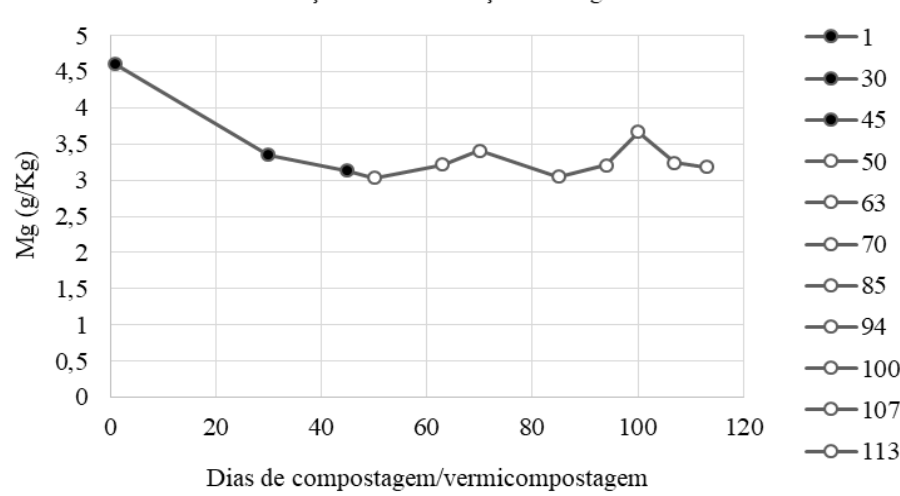

Além de ser fundamental à produção de clorofila, o ferro é componente de muitas enzimas associadas à transferência de energia, redução e fixação de nitrogênio, e formação de lignina (DINIZ, 2017). Diante disso, é ideal que o composto orgânico apresente ferro (Figura 8) em sua composição, mesmo sendo um micronutriente. Verificou-se discreto incremento nas concentrações após o período de vermicompostagem.
Figura 8. Concentração de ferro no material em compostagem/vermicompostagem no decorrer do tempo.

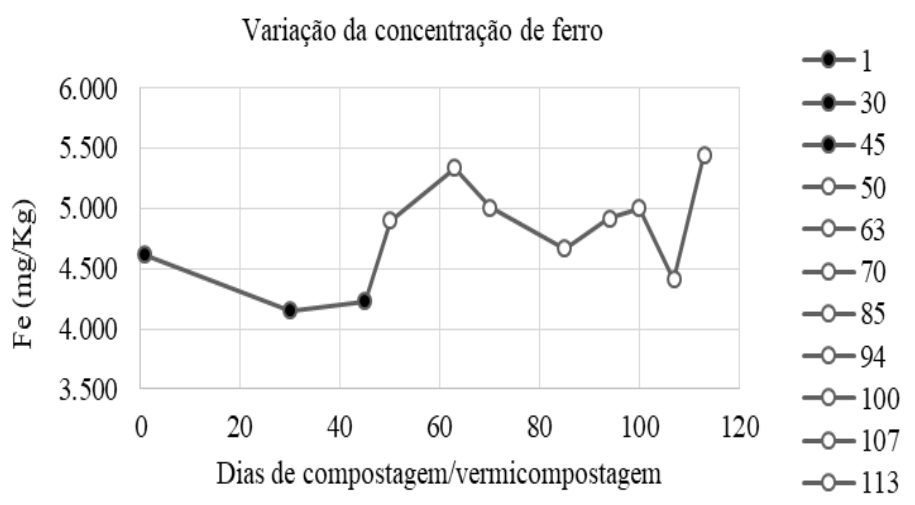

O cobre é um elemento necessário no metabolismo de carboidratos e nitrogênio, de forma que níveis inadequados resultam em plantas atrofiadas. Além disso, o cobre é exigido na síntese de lignina, que é necessária para o fortalecimento das paredes celulares e prevenção ao murchamento (FERNANDES et al., 2016). De modo geral, durante o processo observou-se aumento da disponibilidade de cobre até os 63 dias de compostagem/vermicompostagem (Figura 9). Aos 95 dias, detectou-se a maior concentração deste elemento, sugerindo-se ser o período mais adequado para culturas que necessitam elevadas concentrações.

Figura 9. Concentração de cobre no material em compostagem/vermicompostagem no decorrer do tempo.

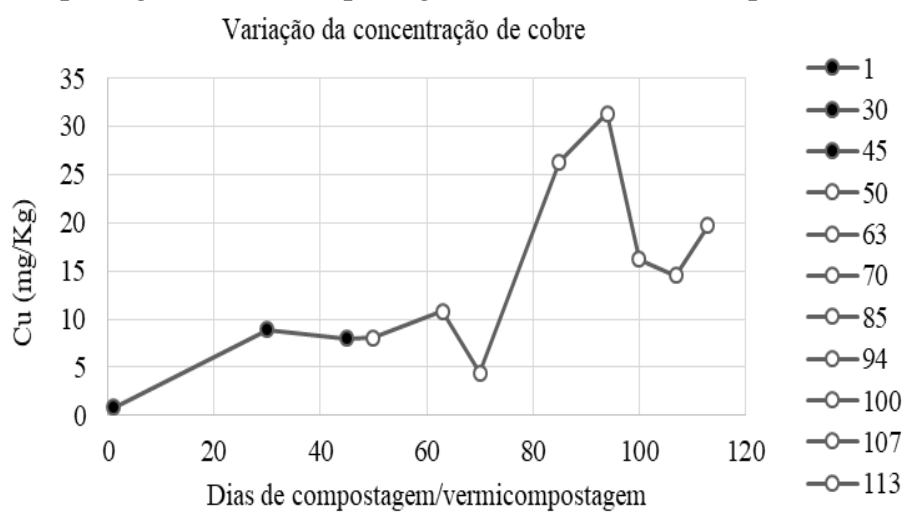

O zinco é um micronutriente com intensa participação nos sistemas enzimáticos que regulam as fases iniciais de crescimento, sendo ainda vital no desenvolvimento das frutas, sementes e sistemas radiculares, na fotossíntese e na proteção das culturas contra o estresse (MELO, 2018). De modo geral, a concentração de zinco (Figura 10) aumentou durante a compostagem e a vermicompostagem.

O Potássio é um nutriente essencial envolvido na respiração e na fotossíntese, muito importante na síntese proteica, além de atuar como cofator enzimático. É um mineral muito solúvel e isso explica o rápido aumento de sua concentração durante a fase de compostagem, visto que foram adicionados vegetais que apresentam elevadas concentrações, como banana, beterraba e batata doce (Figura 11). Adicionalmente, a elevada solubilidade poderia explicar 
também o declínio nas concentrações durante a fase de vermicompostagem por meio de lixiviação (ALVES et al., 2010).

Figura 10. Concentração de zinco no material em compostagem/vermicompostagem no decorrer do tempo.

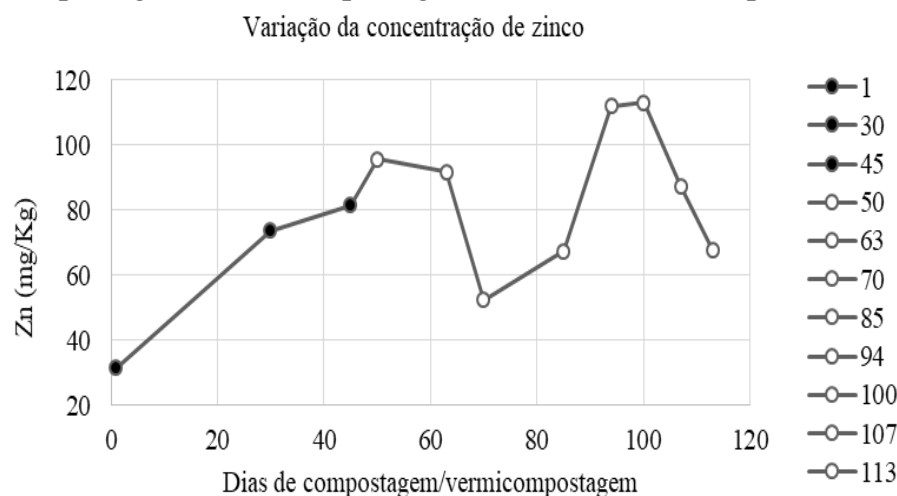

Figura 11. Concentração de potássio no material em compostagem/vermicompostagem no decorrer do tempo.

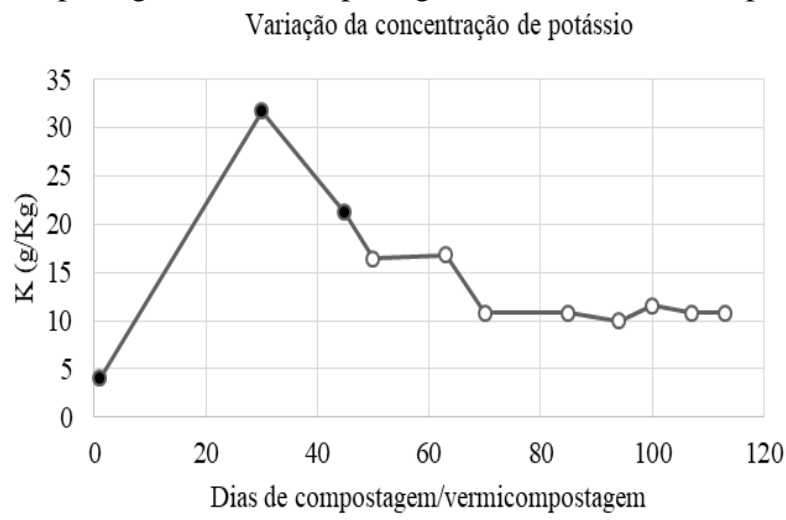

$\rightarrow-1$
$\rightarrow-30$
$\rightarrow-45$
$-0-50$
$-0-63$
$-\infty-70$
$-\infty-85$
$-\infty-94$
$-\infty-100$
$-\infty-107$
$-\infty-113$

\section{CONCLUSÕES}

Os resíduos alimentares podem ser usados para a produção de um composto orgânico fertilizante. A metodologia da compostagem e da vermicompostagem é viável e de fácil aplicação. A vermicompostagem diminuiu a granulometria do composto e o tornou mais escuro, com ausência de odor e melhorou a qualidade nutricional A partir da vermicompostagem obtém-se um substrato com condições nutricionais, de $\mathrm{pH}$ e umidade adequados para o uso na agricultura.

\section{AGRADECIMENTOS}

À Central de Abastecimento do Ceará (CEASA-CE) que cedeu os resíduos orgânicos utilizados nesta pesquisa. Ao sítio Floresta pela concessão de minhocas californianas.

\section{REFERÊNCIAS}

ALVES, A. R.; PASSOS, M. A. A.; HOLANDA, A. C. de. Níveis críticos de potássio para o crescimento inicial de Nim
(Azadirachta indica A. juss.) em solos a zona da mata de Pernambuco. Revista Verde, v. 5, n.1, p. 58-71, 2010.

BACKES, C.; BÔAS, R. L. V.; GODOY, L. J. G. de; VARGAS, P. F.; SANTOS, A. J. M. Determination of growth and nutrient accumulation in Bella Vista onion. Caatinga, v.31, n.1, p. 246-254, 2018.

CEASA - Central de Abastecimento do Ceará S/A. http://www.ceasa-ce.com.br.

CORTEZ, J.W.; ALVES, A. D. de S.; MOURA, M. R. D. de; OLSZEVSKI, N.; NAGAHAMA, H. de J. Atributos físicos do Argissolo Amarelo do semiárido Nordestino sob sistemas de preparo. Revista Brasileira de Ciência do Solo, v. 35, n. 4, p. 1207-1216, 2011.

COTTA, J. A. de O.; CARVALHO, N. L. C.; BRUM, T. da S.; REZENDE, M. O. de O. Compostagem versus vermicompostagem: comparação das técnicas utilizando resíduos vegetais, esterco bovino e serragem. Engenharia Sanitária e Ambiental, v. 20, n. 1, p. 65-68, 2015.

COSTA, F. X.; ALMEIDA, A. C. V. de; MELO FILHO, J. S. de; DANTAS, V. A.; BASILIO, D. de O. Produção de composto de lixo orgânico para a adubação de mudas de cajueiro com fins de arborização do Campus IV da UEPBDOI. Terceiro Incluído, v. 4, n. 2, p. 1-18, 2014. https://doi.org/10.5216/teri.v4i2.35229.

DINIZ, G. A. S.; ARAÚJO NETO, S. E. de; NOVALLI, D. da S.; NOGUEIRA, N. T.; SILVA, I. F. da.Qualityindex and harvest maturityof Eugenia cibrat a fruits. Revista Brasileira de $\begin{array}{lllll}\text { Fruticultura, } & \text { v. } \quad 39, \quad \text { n. } & \text { SPE, } & 2017 .\end{array}$ http://dx.doi.org/10.1590/0100-29452017859.

DORES-SILVA, P. R.; LANDGRAF, M. D.; REZENDE, M. O. de O. Processo de estabilização de resíduos orgânicos: vermicompostagem versus compostagem. Química Nova, v. 36, n. 5 , p. $640-645,2013$.

FERNANDES, F. D.; GUIMARÃES JÚNIOR, R.; VIEIRA, E. A.; FIALHO, J. de F.; MALAQUIAS, J. V. Produtividade e valor nutricional da parte aérea e de raízes tuberosas de oito genótipos de mandioca de indústria. Revista Brasileira de Saúde e Produção Animal, v. 17, n. 1, p. 1-12, 2016. http://dx.doi.org/10.1590/S1519-99402016000100001.

JARA, P. T. C.; RUBIO, F.; SANTOS, F. T. dos; LORIN, H. E. F.; LUIZ, F. N. Vermicompostagem de resíduos de crambe na produção de mudas de rúcula. Ciências Agrárias, v. 40, n. 1, p. 45-52, 2017. http://dx.doi.org/10.19084/RCA15148.

LOUREIRO, D. C.; AQUINO, A. M. de, ZONTA, E.; LIMA, E. Compostagem e vermicompostagem de resíduos domiciliares com esterco bovino para a produção de insumo orgânico. Pesquisa agropecuária brasileira, v.42, n.7, p. 1043-1048, 2007. http://dx.doi.org/10.1590/S0100-204X2007000700018. 
MALAFAIA, G.; JORDÃO, C. R.; ARAÚJO, F. G. de; LEANDRO, W. M.; RODRIGUES, A. S. de L. Vermicompostagem de lodo de curtume em associação com esterco bovino utilizando Eisenia foetida. Engenharia Sanitária e Ambiental, v. 20, n. 4, p. 709-716, 2015. http://dx.doi.org/10.1590/S1413-41522015020040134645.

MALAVOLTA, E.; VITTI, G. C.; OLIVEIRA, S. A. de. Avaliação do estado nutricional das plantas: princípios e aplicações. Piracicaba: Editora Potafos, 1997. 319p.

MELO, F. de B.; BASTOS, E. A.; CARDOSO, M. J.; RIBEIRO, V. Q. Cowpea response to phosphorus and zinc. Caatinga, $\quad$ v. $31, \quad$ n. $1, \quad$ p. 240-245, 2018. http://dx.doi.org/10.1590/1983-21252018v31n128rc

MILLÁN, F.; PRATO, J. G.; CRUZ, Y. la, SÁNCHEZ, A. Estudio metodológico sobre la medición de $\mathrm{pH}$ y conductividad eléctrica em muestras de compost. Revista Colombiana de Química, v. 47, n. 2, p. 21-27, 2017. http://dx.doi.org/10.15446/rev.colomb.quim.v47n2.67338.

MOURA, L. B. de; FREIRE, D. S.; ROCHA, I. da S.; SILVA, J. C. I. da; SANTOS, T. V. Gerenciamento de resíduos em empresas do setor hortifrúti localizadas na região do Cariri Ceará. Revista Verde, v. 8, n. 5, p. 21-24, 2013.

ORRICO JÚNIOR, M. A. P.; ORRICO, A. C. A.; LUCAS JÚNIOR, J. de. Compostagem dos resíduos da produção avícola: cama de frangos e carcaças de aves. Engenharia Agrícola, v. 30, n. 3, p. 538-545, 2010.

ORRICO JÚNIOR, M. A. P.; ORRICO, A. C. A.; LUCAS JUNIOR, J. de; SAMPAIO, A. A. M.; FERNANDES, A. R. M.; OLIVEIRA, E. A. de. Compostagem dos dejetos da bovinocultura de corte: influência do período, do genótipo e da dieta. Revista Brasileira de Zootecnia, v. 41, n. 5, p. 1301-1307, 2012.

PRADO, R. de M.; NATALE, W. Calagem na nutrição de cálcio e no desenvolvimento do sistema radicular da goiabeira. Pesquisa Agropecuária Brasileira, v. 39, n. 10, p. 1007, 1012, 2004. http://dx.doi.org/10.1590/S0100204X2004001000008.

SILVA, C. D. da; COSTA, L. M. da; MATOS, A. T. de; CECON, P. R.; SILVA, D. D. Vermicompostagem de lodo de esgoto urbano e bagaço de cana-de-açúcar. Revista Brasileira de Engenharia Agrícola e Ambiental, v. 6, n. 3, p. 487-491, 2002. http://dx.doi.org/10.1590/S1415-43662002000300018.

SOUZA, F. I. de; GRANGEIRO, L. C.; SOUZA, V. de F. L.; GONÇALVEZ, F. das C.; OLIVEIRA, F. H. T. de; JESUS, P. M. M. de. Agronomic performance of Italian zucchini as a function of phosphate fertilization. Revista Brasileira de Engenharia Agrícola e Ambiental, v. 22, n. 3, p. 206-211, 2018. http://dx.doi.org/10.1590/1807-1929/agriambi.v22n3p206-211.
VALENTE, B. S.; XAVIER, E. G.; PEREIRA, H. da S.; ANDREAZZA, R.; GOMES, M. C. Variabilidade na composição química de vermicompostos comerciais. Revista Verde, v. 13, n.4, p. 557-562, 2018. http://dx.doi.org/10.18378/rvads.v13i4.5354.

VIONE, E. L. B.; SILVA, L. S. da; CARGNELUTTI FILHO, A.; AITA, N. T.; MORAIS, A. de F. de; SILVA, A. A. K. da. Caracterização química de compostos e vermicompostos produzidos com casca de arroz e dejetos animais. Ceres, v. 65, n. $1, \quad$ p. $65-73, \quad 2018$. http://dx.doi.org/10.1590/0034737x201865010009. 